\title{
Design of High Precision Temperature and Pressure Closed-Loop Control System for Methane Carbon Isotope Ratio Measurement by Laser Absorption Spectroscopy
}

\author{
Liu Xu ${ }^{1,2,5}$, Zhang Zhirong ${ }^{1,2,3,4 *}$, Sun Pengshuai ${ }^{1,3}$, Zhang Lewen ${ }^{1,2}$, Pang Tao ${ }^{1,3}$, \\ Xia Hua ${ }^{1,3}$, Wu Bian ${ }^{1,3}$, Shu Zhifeng ${ }^{6}$, Shu Chimin ${ }^{7}$ \\ 'Anhui Provincial Key Laboratory of Photonic Devices and Material, Anhui Institute of Optics and Fine Mechanics, \\ Hefei Institutes of Physical Science, Chinese Academy of Science, Hefei 230031, China \\ ${ }^{2}$ University of Science and Technology of China, Hefei 230026, China \\ ${ }^{3}$ Key Lab of Environmental Optics \& Technology, Anhui Institute of Optics and Fine Mechanics, \\ Chinese Academy of Sciences, Hefei 230031, China \\ ${ }^{4}$ Advanced Laserer Tenonology Laboratory of Anhui Province, Heifei 230037, China \\ ${ }^{5}$ School of Electronic and electrical Engineering, Bengbu University, Bengbu 233030, China \\ ${ }^{6}$ School of Atmospheric Physics, Nanjing University of Information Science \& Technology, \\ Ningliu Road No. 219, Nanjing, China, 210044 \\ ${ }^{7}$ Department of Safety Health and Environmental Engineering, Yunlin University of Science and Technology, \\ Yunlin, Taiwan 64002, China
}

Received: 30 April 2021

Accepted: 17 July 2021

\begin{abstract}
In order to achieve the accurate measurement of gas stable isotope, according to the structure of gas cavity and the characteristics of optical elements, a constant temperature and pressure gas isotope measurement experimental system based on tunable diode laser absorption spectroscopy (TDLAS) technology is designed, which can achieve high-precision and stable control of temperature and pressure in the box. The hardware circuit system including high-precision constant-current source, two-channel temperature sampling module, conditioning circuit and pressure control circuit is designed in the system. The corresponding system closed-loop control software is developed to ensure the stability of the temperature and pressure of the optical cavity. Through the experimental verification, the temperature is controlled at $35^{\circ} \mathrm{C}$ and the pressure is controlled at 150 mbar in the present work. The measurement results verified the stability of the temperature and pressure system, as follows: the optimal temperature fluctuation control is $\pm 0.005^{\circ} \mathrm{C}$ and the pressure stability is $\pm 0.1 \mathrm{mbar}$. Then, in our experiment, the $\mathrm{CH}_{4}$ standard gas is introduced to measure carbon isotope $\left({ }^{12} \mathrm{CH}_{4}\right.$ and $\left.{ }^{13} \mathrm{CH}_{4}\right)$. The results
\end{abstract}

*e-mail: zhangzr@aiofm.ac.cn 
clearly show that the control system is sufficiently stable to be used and the $\delta^{13} \mathrm{C}$ value can reach $0.52 \%$ according to the Allan variance.

Keywords: tunable diode laser absorption spectroscopy (TDLAS), $\mathrm{CH}_{4}$ carbon isotope, temperature and pressure, closed-loop control, Allan variance

\section{Introduction}

With the progress of our society, more and more attention has been paid to environmental problems. Global warming caused by greenhouse gases has become an important environmental problem in the whole world [1-4]. The General Assembly adopted the United Nations Framework Convention on Climate Change on May 9, 1992 [5], with the ultimate goal of reducing greenhouse gas emissions, reducing the harm caused by human activities to the climate system, and slowing down climate change. $\mathrm{CH}_{4}$ is often regarded as the second most important greenhouse gas after $\mathrm{CO}_{2}$ in contributing to global warming, accounting for $25 \% \sim 28 \%$ of direct emissions [6-7]. With the increase of global natural gas consumption, the risk of future methane leakage is huge [8]. The largest anthropogenic methane emission source in China is gas emission from coal mining, which is characterized by the difficulty in methane recovery and utilization .

In order to control greenhouse gas emissions [910], it is necessary to better understand the distribution law of natural carbon sources and sinks, which requires active measurement technology of greenhouse gas source emissions and ecological flux [11-13]. Isotopes are chemical elements whose atomic mass and radioactivity are different but whose physical and chemical properties are the same. Changes in isotopic abundance carry information about a series of processes [14]. Stable Isotope is the atmosphere and the ecological system of material flow and flux "fingerprints" of instruction material [15]. Stable isotopes, which do not show fractionation during migration and reaction, have been widely used in the analysis of various sourcetracing problems [16-17]. In recent years, with the rapid development of mass spectrometry (Isotope Ratio Mass Spectrometry, IRMS), the application of stable Isotope has been greatly broaden and paid more and more attention in agriculture, environmental science and other fields [18-20]. However, commercial IRMS instruments are not suitable for continuous and rapid in-situ measurements due to their large size, high cost, complex and long analytical process. Furthermore, the conventional IRMS method cannot separate isotopic information of the same quality, such as ${ }^{17} \mathrm{O}^{12} \mathrm{C}^{16} \mathrm{O}$ and ${ }^{16} \mathrm{O}^{13} \mathrm{C}^{16} \mathrm{O}$ or ${ }^{13} \mathrm{CH}_{4}$ and ${ }^{12} \mathrm{CH}_{3} \mathrm{D}$.

In absorption spectroscopy, in contrast, different isotopic molecular species can be distinguished easily irrespective of their masses if appropriate absorption lines are selected. In recent years, Tunable Diode Laser Absorption Spectroscopy (TDLAS) has developed rapidly with advantages [21-23] and solved the above problems efficiently. When TDLAS is used to measure isotopic abundance, spectral line width and line type are affected by natural broadening, Doppler broadening and collision broadening [24]. Qi Rubin et al. [25] simulated the absorption spectrum of $\mathrm{H}_{2} \mathrm{O}$ in the spectral band under different pressures and temperatures, and studied the variation law of the absorption spectrum with pressure and temperature. Chen Zhou et al. [26] verified the influence of temperature and pressure on gas linear peak value by analyzing the absorption spectral line of hydrogen fluoride when temperature and pressure change. Therefore, in order to obtain accurate and stable detection results, the temperature and pressure changes of sample gas become the main factors affecting the measurement results when isotope abundance is detected. In this paper, $\mathrm{CH}_{4}$ carbon isotope $\left({ }^{12} \mathrm{CH}_{4}\right.$ and $\left.{ }^{13} \mathrm{CH}_{4}\right)$ are selected as the research object, and the simulation results of line broadening under different pressures are analyzed. Then, a set of high precision temperature and pressure constant control system for the optical and mechanical structure of the absorption cavity in the TDLAS system is designed. It includes high precision constant current source, two temperature sampling module, pressure control circuit, and PID control method. Due to the high concentration of gas in the application environment, $5000 \mathrm{ppm}$ methane gas is selected as the research object to measure its isotope. In the following, we describe the techniques for precise isotope measurements employed in this study in more detail. The ratio of ${ }^{13} \mathrm{CH}_{4} /{ }^{12} \mathrm{CH}_{4}$ in two high concentration methane samples was analyzed by TDLAS under the above temperature and pressure control conditions, and the precision and accuracy of the method were evaluated by the experimental results.

Basic Principle

\section{Principle of Absorption Spectrum}

TDLAS gas concentration detection technology makes full use of the fast wavelength tuning and narrow linewidth characteristics of semiconductor lasers to obtain the absorption spectrum of selected target gas, so as to make qualitative or quantitative analysis of the measured gas. According to the Beer-Lambert law [27], when the incident light with intensity $I_{0}(v)$ passes through the uniform gas medium with optical path $\mathrm{L}$ and is absorbed by the gas with concentration $C$, the transmitted light intensity $I_{t}(v)$ can be expressed as formula (1): 


$$
\mathrm{I}_{t}=\mathrm{I}_{0} \exp [-S(T) C P L \varphi(\mathrm{v})]
$$

In the formula, $\mathrm{S}(\mathrm{T})$ is the absorption line strength of the gas measured at $v$ of the frequency, $\mathrm{P}$ is the pressure of the gas, $\mathrm{T}$ is the temperature of the gas measured at $v$, and $\varphi(v)$ is the absorption line. This also indicates that temperature and pressure changes will have an impact on the measurement results.

Since the absorption line function is integrated in the whole frequency domain of $\int_{-\infty}^{+\infty} \phi(v) d v=1$, the logarithm of both sides of equation (1) is taken, and the integrated value is expressed by absorbance $A$, the gas concentration obtained by integration in the whole frequency domain is as follows:

$$
\mathrm{C}=\mathrm{A} / \mathrm{PS}(T) L
$$

\section{Isotopic Abundance Calculation}

This study mainly measures the methane isotope ratio of ${ }^{13} \mathrm{CH}_{4} /{ }^{12} \mathrm{CH}_{4}$ in $\mathrm{CH}_{4}$ gas, which can be used to measure the change of the isotope composition in the sample. Usually, the isotope ratio $\mathrm{Z}$ is defined as the concentration ratio of heavy isotope atoms to light isotope atoms, such as ${ }^{13} \mathrm{CH}_{4}{ }^{12} \mathrm{CH}_{4}$. However, in the actual measurement, the value of $\mathrm{Z}$ changes little and the measurement is difficult. At present, the relative measurement method is widely used to express the isotopic abundance. The relative measurement method is to calculate the thousand points of the relative deviation using the $\mathrm{Z}$ value of the studied gas and the $\mathrm{Z}$ reference value of the standard gas. The thousand points of the relative deviation is expressed by the delta value $(\delta)$. For example, the abundance value of carbon isotope $\left({ }^{13} \mathrm{C}\right)$ in the measured sample can be described as $\delta^{13} \mathrm{C}$ as follows,

$$
\delta^{13} C=\left[\frac{Z_{\text {sample }}}{Z_{P D B}}-1\right] \times 1000 \%
$$

In formula (3), $Z_{\text {sample }}$ represents the ratio of isotopes in the sample, while $Z_{\mathrm{PDB}}$ represents the ratio of isotopes in the standard.

\section{Selection of $\mathrm{CH}_{4}$ Isotopic Measurement Spectral Lines}

The selection of isotopic measurement spectral lines is particularly important for obtaining better detection sensitivity and accuracy. The general rules of spectral line selection are as follows: Firstly, avoid the interference of absorption spectral lines of other gas molecules and their own absorption spectral lines; Secondly, the isotope absorption spectral lines are adjacent to each other and within the scanning range of a single laser; Finally, the product of isotope abundance and absorption line strength is close to ensure that the measured absorption signal is in the same order of magnitude and the signal-to-noise ratio is consistent. Therefore, the absorption spectral lines between $1658.5 \mathrm{~nm}$ and $1659.5 \mathrm{~nm}$ from the HITRAN database [28] are shown in Fig. 1, respectively. Meanwhile, according to the actual situation, the isotopic molecular content of ${ }^{13} \mathrm{CH}_{4}$ is generally two or three orders of magnitude lower than that of ${ }^{12} \mathrm{CH}_{4}$. So according to the last rule, the absorption intensity of ${ }^{13} \mathrm{CH}_{4}$ should be about 100 times higher than that of ${ }^{12} \mathrm{CH}_{4}$. According to Fig. 1, Table 1 lists a pair of selected methane transitions, $\mathrm{A}$ and $\mathrm{B}$, of ${ }^{12} \mathrm{CH}_{4}$ and ${ }^{13} \mathrm{CH}_{4}$, respectively.

Under the HITRAN database, the direct absorption spectra of ${ }^{13} \mathrm{CH}_{4}$ and ${ }^{12} \mathrm{CH}_{4}$ at room temperature of $296 \mathrm{~K}$, pressure of $100-1000$ mbar (step by step of $100 \mathrm{mbar}$ ) and optical path of $20 \mathrm{~m}$ are obtained through

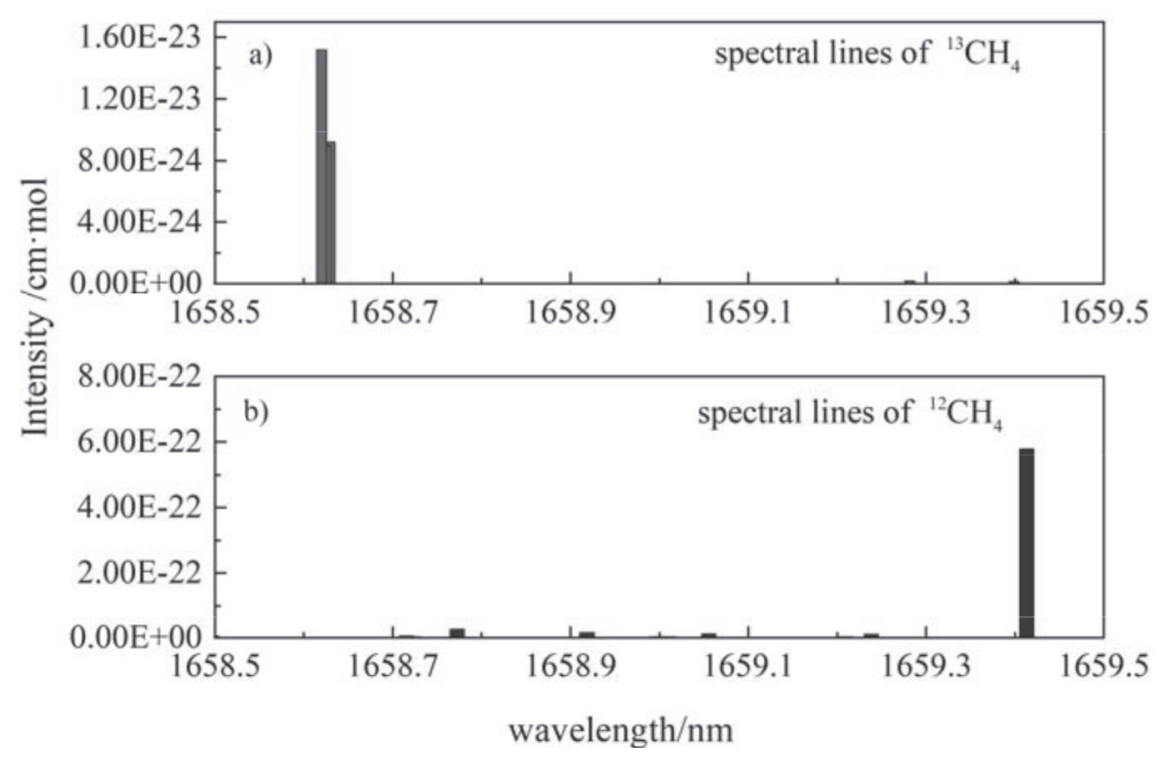

Fig. 1. Spectral line intensity of methane carbon isotopes in HITRAN database at wavelength $1658 \mathrm{~nm}$. 
Table 1. Spectroscopic Data of Selected ${ }^{12} \mathrm{CH}_{4}$ and ${ }^{13} \mathrm{CH}_{4}$.

\begin{tabular}{|c|c|c|c|c|c|c|}
\hline & & Isotope & $\begin{array}{l}\text { Wavelength } \\
(\mathrm{nm})\end{array}$ & $\begin{array}{l}\text { Wavenumber } \\
\left(\mathrm{cm}^{-1}\right)\end{array}$ & $\begin{array}{c}\text { Intensity } \\
\left(\mathrm{cm}^{-1} /\left(\text { molecule } \mathrm{cm}^{-2}\right)\right)\end{array}$ & $\begin{array}{c}E^{\prime \prime} \\
\left(\mathrm{cm}^{-1}\right)\end{array}$ \\
\hline \multirow{4}{*}{$\mathrm{CH}_{4}$} & \multirow{3}{*}{ A } & \multirow{3}{*}{${ }^{13} \mathrm{CH}_{4}$} & 1658.629 & 6029.072 & 7.794E-22 & 62.8787 \\
\hline & & & 1658.625 & 6029.089 & $7.802 \mathrm{E}-22$ & 62.8797 \\
\hline & & & 1658.620 & 6029.107 & $1.283 \mathrm{E}-21$ & 62.8811 \\
\hline & B & ${ }^{12} \mathrm{CH}_{4}$ & 1658.772 & 6028.553 & $2.692 \mathrm{E}-23$ & 104.7728 \\
\hline
\end{tabular}

simulation. It can be seen from the simulation results in Fig. 2 the absorption strength of the selected isotope absorption lines at $1658.62 \mathrm{~nm}\left({ }^{13} \mathrm{CH}_{4}\right)$ and $1658.77 \mathrm{~nm}$ $\left({ }^{12} \mathrm{CH}_{4}\right)$ is not significantly different from that at the standard abundance, and the absorption line shape of ${ }^{13} \mathrm{CH}_{4}$ and ${ }^{12} \mathrm{CH}_{4}$ lines is relatively independent when the pressure range is from 100 mbar to 200 mbar. Under this pressure range, the three absorption spectral lines of ${ }^{13} \mathrm{CH}_{4}$ are spaced less than $0.01 \mathrm{~nm}$ apart and cannot be separated. The spectral lines can be regarded as one absorption spectral line, and its intensity is equal to the sum of these three spectral lines, 2.8426E-21. The measurement results of known gas concentrations can be verified that this kind of treatment is correct. And the cavity pressure should be controlled at $100 \mathrm{mbar}$ in this situation.

\section{Experimental Device}

\section{Structure Design}

The schematic diagram of the experimental system is shown in Fig. 3. The system is mainly composed of three parts: light source module, temperature and pressure control module, and signal processing module. In the first part, the signal generator generates a sawtooth scanning signal and a sinusoidal modulation signal to scan the isotope absorption line pair, simultaneously. The tail fiber output DFB laser is driven by the lowpower laser controller developed by the research group, and coupled into the constant pressure and temperature optical multipass cavity under the control modules. The temperature and pressure control module is composed of multi-channel temperature sensors, capacitive pressure sensors and a homemade temperature control box. In addition, the temperature control system is formed by the joint action of double-sided Peltier and two fans to ensure the stability and uniform ambient temperature, which ensures the stability of the optical mechanical structure. The gas absorption cell is placed in the box to ensure the temperature of the measured gas. The Proportion Integration Differentiation (PID) control method and controllable solenoid valve are used to realize high precision control of temperature and pressure. The photoelectric detector receives the optical signal and converts it into an electrical signal. After amplification, the signal is sent to the phase-locked circuit together with the reference signal generated by the signal generator for demodulation to obtain the

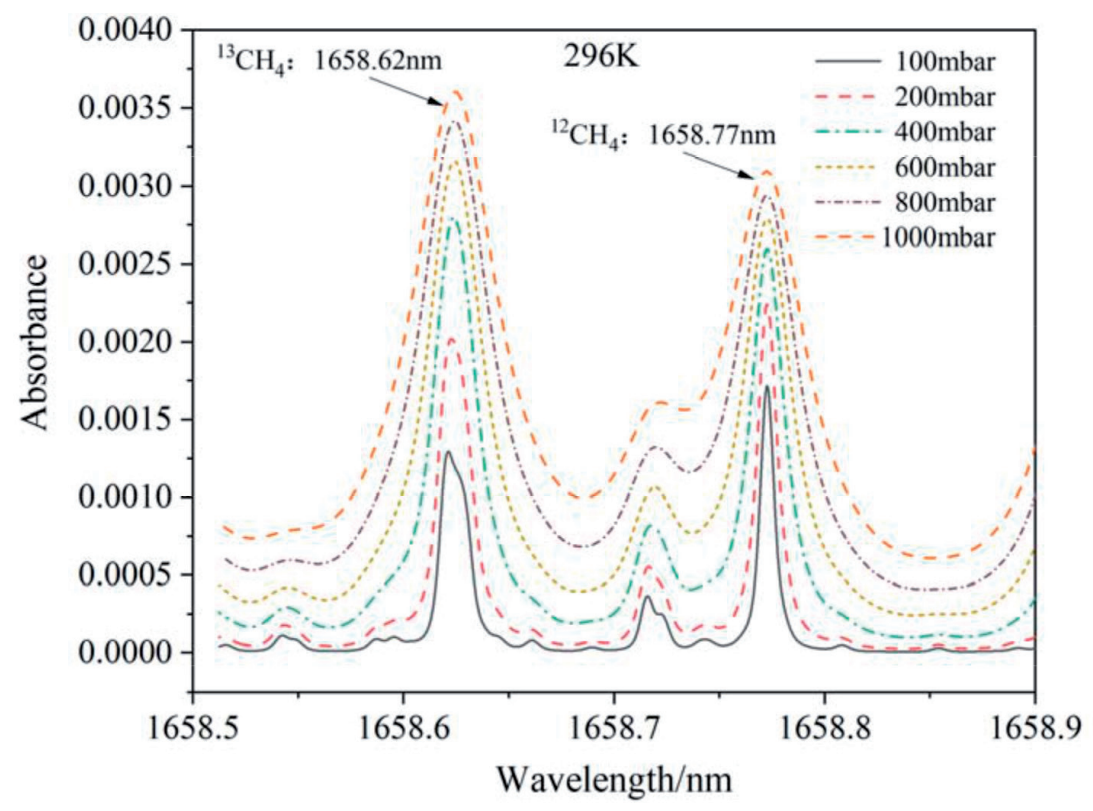

Fig. 2. $\mathrm{CH}_{4}$ simulation results at different pressures near $1658 \mathrm{~nm}$. 


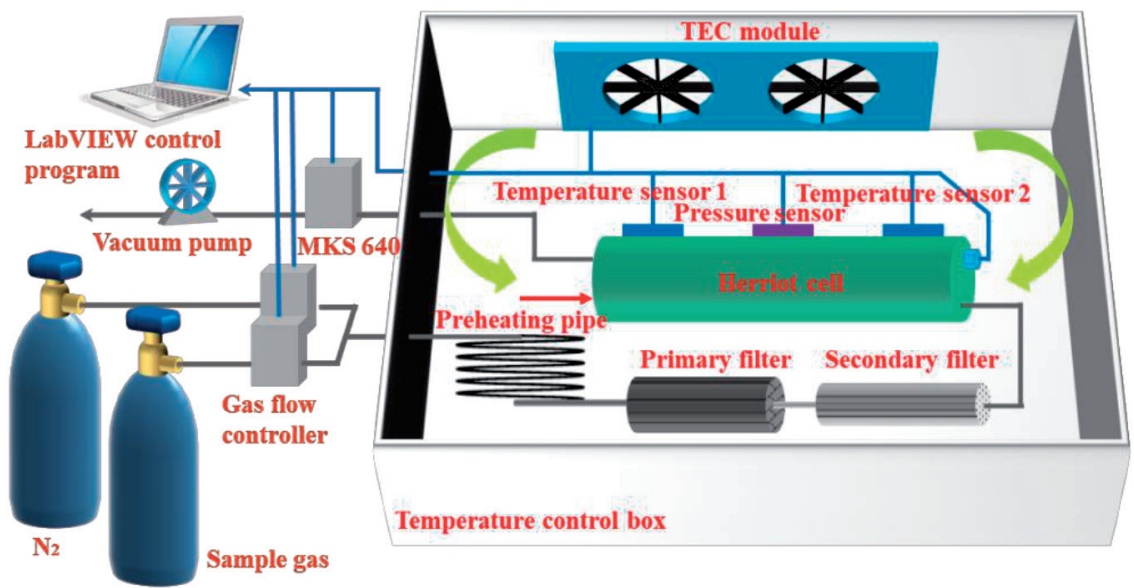

Fig. 3. Schematic diagram of isotopic measurement experiment system.

second harmonic signal. Then the data is collected by the high-speed data acquisition card and the isotope abundance of ${ }^{13} \mathrm{CH}_{4}$ is calculated. In this experiment, ${ }^{13} \mathrm{CH}_{4}$ standard gas with a concentration of $5000 \mathrm{ppm}$ is used as the experimental gas, and the source was a DFB laser with a central wavelength of $1.658 \mathrm{~nm}$. The ${ }^{13} \mathrm{CH}_{4}$ isotope is measured under a constant temperature $35^{\circ} \mathrm{C}$ and pressure of 150 mbar.

\section{Design of Temperature and Pressure Control System}

Temperature and pressure control flow diagram is shown in Fig. 4. The temperature and pressure values inside the cavity are collected by the PT100 thermistor and pressure sensor in real time, and transmitted to software configuration management (SCM) through high-precision analog-to-digital converter (AD) chip (LTC2400). The PID control software in STM32 control chip controls the temperature and pressure circuit module by outputting pulse width modulation (PWM) waveform according to the set values. The heating or cooling capacity of TEC, axial fan speed and the proportional opening of solenoid valve (MKS640) are controlled by PWM waveform pulse width and amplitude, so as to adjust the cavity temperature and gas pressure. Finally, the temperature and pressure of the cavity are at the set value and at a stable value. The cavity temperature and pressure control circuits will be described in detail in the following part.

\section{Temperature and Pressure Control Circuits Design}

The constant-current source is located in the most advanced stage of the circuit, which directly affects the stability and accuracy of the whole system. The temperature acquisition and signal conditioning circuit is shown in Fig. 5. TI's LMP7704MT has very low input bias current, input current noise and input voltage noise. AD780 bandgap voltage reference is a high precision voltage source, which has the characteristics of small initial error, small temperature drift and low output noise. Its maximum temperature drift is $3 \mathrm{ppm} /{ }^{\circ} \mathrm{C}$, and the output precision is $2.5 \mathrm{~V} \pm 1 \mathrm{mV}$. Therefore, it is selected in the design to provide the reference voltage $\mathrm{V}_{\mathrm{REF}}$. The selection and design of temperature sensors is crucial to achieve the stability requirement of $0.1 \%$. Since ITS-90 international temperature scale uses platinum resistance as the reference test instrument,

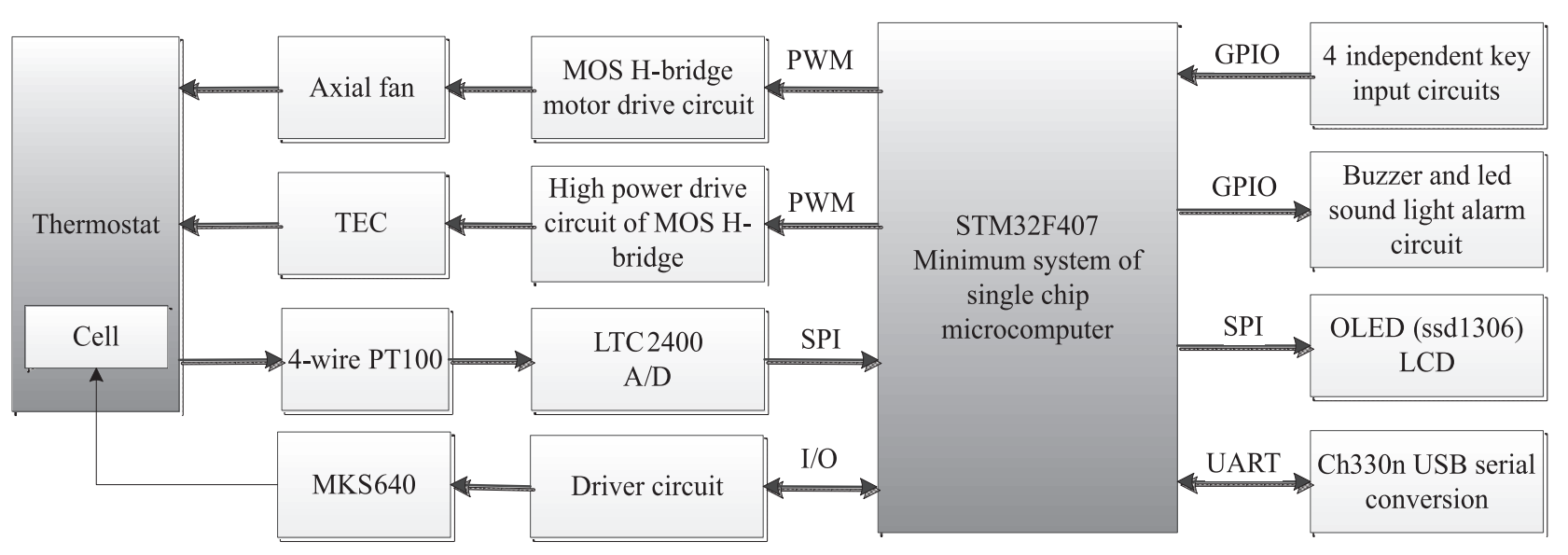

Fig. 4. Design block diagram of voltage stabilizing control system. 


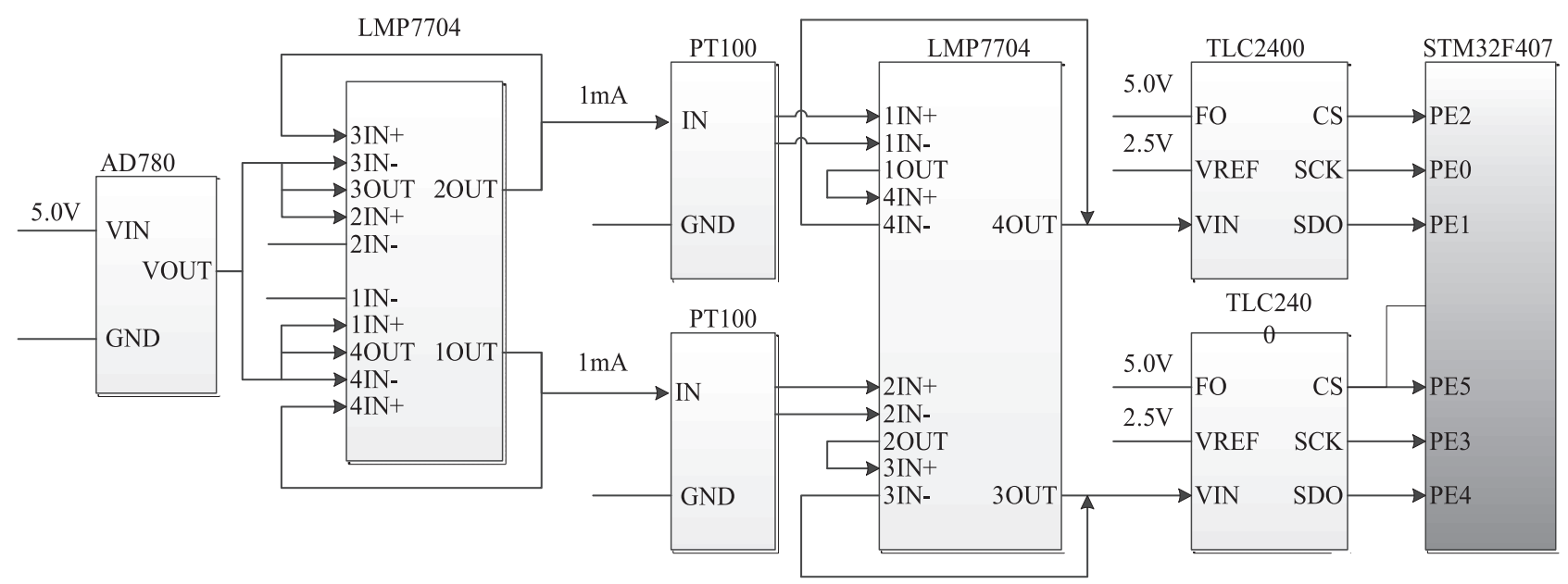

Fig. 5. Temperature acquisition and signal conditioning circuit.

the real-time temperature monitoring inside the cavity system also selects grade A platinum thermistor PT100 as the component. In addition, the improved PT100 twoway four-wire connection mode is adopted to achieve high-precision temperature measurement in this scheme. Two compensation wires are connected on both sides of PT100, respectively. It is worth noting that the constant current source determines the accuracy of temperature measurement inside the cavity. So, according to the experimental device and measurement accuracy in this experiment, it is set to $1 \mathrm{~mA}$. After RC filtering, one stage operational amplifier and two stage operational amplifier amplifying, the temperature measurement weak voltage value is sent to the $\mathrm{A} / \mathrm{D}$ acquisition circuit composed of LTC2400 to complete the analog-to-digital conversion. In the control circuit part, two H-bridge circuits are used to control the positive and negative output of current and drive the high power TEC, thus achieving the function of switching heating and cooling [29].

The pressure control circuit is shown in Fig. 6. Considering the accuracy, acquisition and set both chips using REF195 high precision voltage reference source voltage benchmark, chip peripheral increased by high frequency, low resistance and high capacity of tantalum capacitor and its decoupling capacitor to reduce digital signal interference. AD5689 high-precision 16-bit DAC chip is used for analog voltage output to set the MKS640 different flow values. Ad7190 is used to collect the pressure output value of MKS640 device and feedback the current pressure value to the control system. In consideration of the level difference between isolated power supply and microcontroller, digital isolator ADuM1400 and ADuM1411 chips are used for signal conversion.

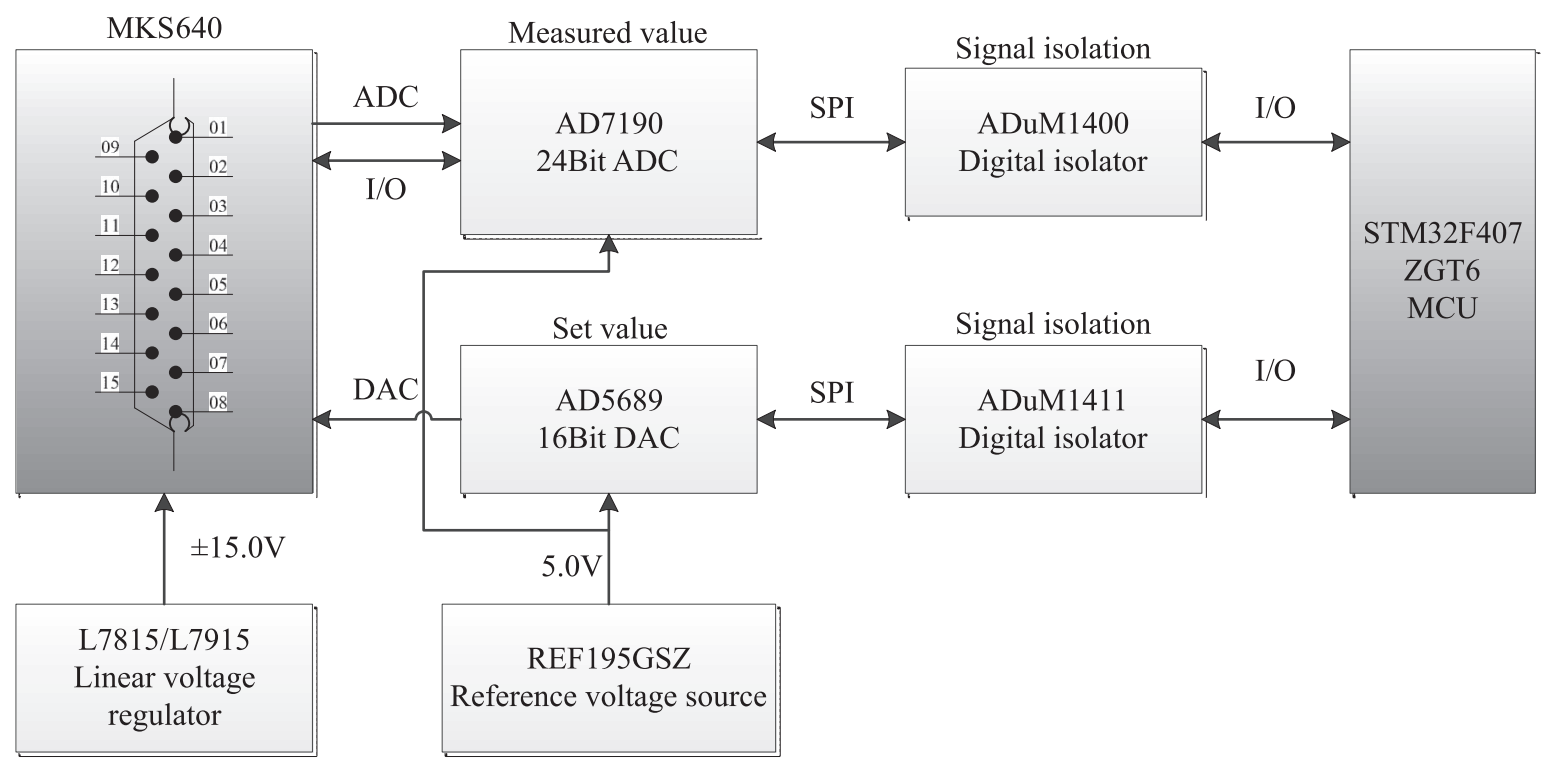

Fig. 6. Pressure control circuit design. 


\section{PID Algorithm}

The core of the control system is digital PID control part. It is a kind of adjustability of the linear additive feedback of the three control components: Proportion, Integration and Differentiation. The linear combination of $\mathrm{u}(\mathrm{t})$ can be controlled according to the control deviation $\mathrm{e}(\mathrm{t})=\mathrm{r}(\mathrm{t})-\mathrm{y}(\mathrm{t})$ formed by the given value $\mathrm{R}(\mathrm{t})$ and the actual output value $y(t)$.

The mathematical model of PID control can be expressed as,

$$
U=K_{p}\left[e(t)+\frac{1}{T_{i}} \int_{0}^{t} e(t) \mathrm{d} t+T_{d} \frac{\mathrm{d} e(t)}{\mathrm{d} t}\right]
$$

Its transfer function can be expressed as

$$
G(s)=K_{p}\left(1+\frac{1}{T_{d} s}+T_{d} s\right)
$$

In formula (4), $\mathrm{K}_{\mathrm{p}}$ is the proportional coefficient, $T_{i}$ is the integral constant, and $T_{d}$ is the differential constant. It can be seen from equations (4) and (5) that the proportion part will reduce the steady-state error, but will not completely eliminate it. The integral part eliminates the steady-state error of the system, but it will cause over regulation. The differentiation part reflects the change trend, but it will introduce high frequency interference. Therefore, the balance adjustment of the system can only be achieved by combining these three parts. As the output of positional PID control algorithm is related to each state in the past, the error needs to be accumulated during calculation, so it is easy to produce too much overshoot. Therefore, the incremental PID control algorithm is adopted in the design to avoid the calculation error or fault leading to the output fluctuations, and even lead to the damage of the actuator.

\section{Experimental Results and Analysis}

\section{Schematic}

As shown in Fig. 7, the light source is a DFB laser with fiber output, and its central wavelength is $1658 \mathrm{~nm}$, the temperature and current of the DFB laser are controlled by the high-precision laser driver developed by the research group. The output laser enters the gas absorption cavity through the optical fiber, and the photodetector in the cavity receives the optical signal after passing through the gas sample. After photoelectric conversion, part of the electrical signal enters the phase-locked circuit through the preamplifier circuit to demodulate the harmonic signal, and part enters the low-pass filter signal to filter out the high-frequency modulation and noise signal in the signal to obtain the triangular wave signal. Finally, the multi-channel data acquisition card collects the two signals and transmits them to the upper computer to complete the calculation of methane concentration and $\delta^{13} \mathrm{CH}_{4}$. The stability of the system and the effect of temperature and pressure control on isotope measurement are tested after three hours of continuous operation.

\section{Temperature and Pressure Stability Analysis}

In order to verify the stability of temperature and pressure control inside the cavity, the temperature and pressure values are set at $35^{\circ} \mathrm{C}$ and $150 \mathrm{mbar}$ respectively. The measurement results are recorded during 3 hours of stable operation. From Fig. 8a), it can be seen that the temperature is basically stable at $35^{\circ} \mathrm{C}$, the fluctuation of temperature control is $0.005^{\circ} \mathrm{C}$, and the standard deviation $(\delta)$ is 0.003 . From Fig. $8 b$ ), the pressure fluctuation is $150 \mathrm{mbar} \pm 0.1 \mathrm{mbar}$ and $\delta$ is 0.03 . Overall, the temperature and pressure control of the instrument has reached the requirements of high precision for a long time, and is not affected by the change of external ambient temperature. Furthermore,

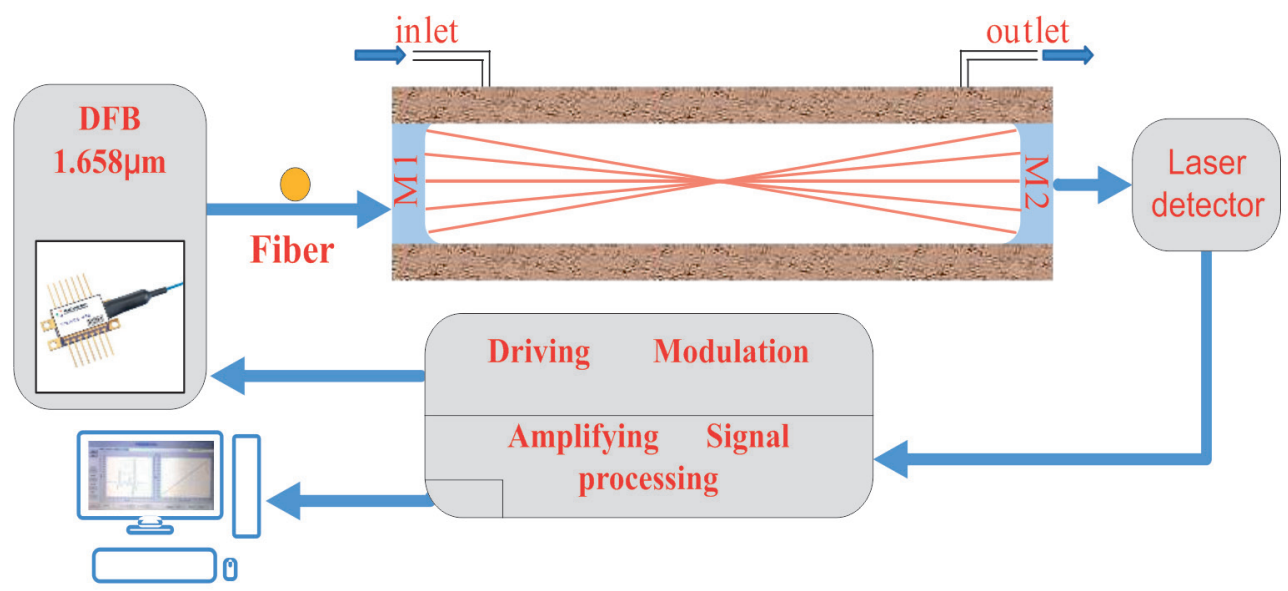

Fig. 7. Schematic diagram of experimental system. 


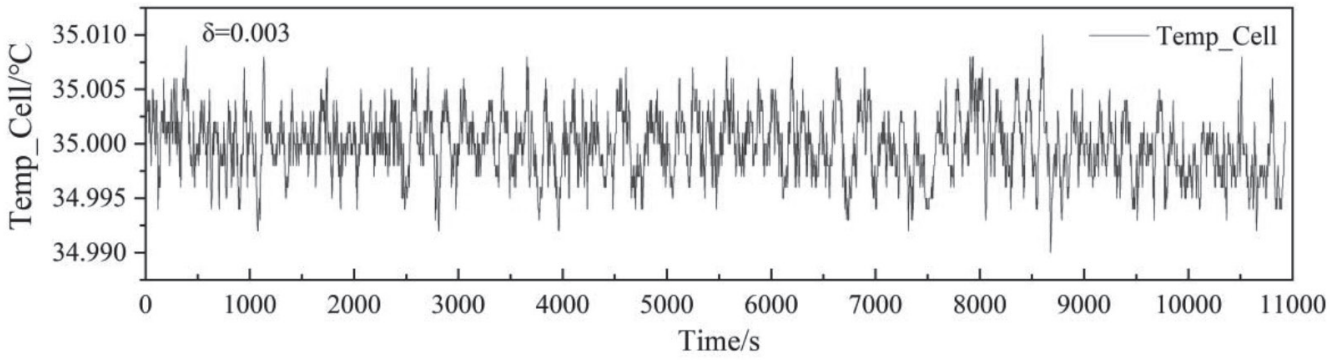

(a) Cavity temperature

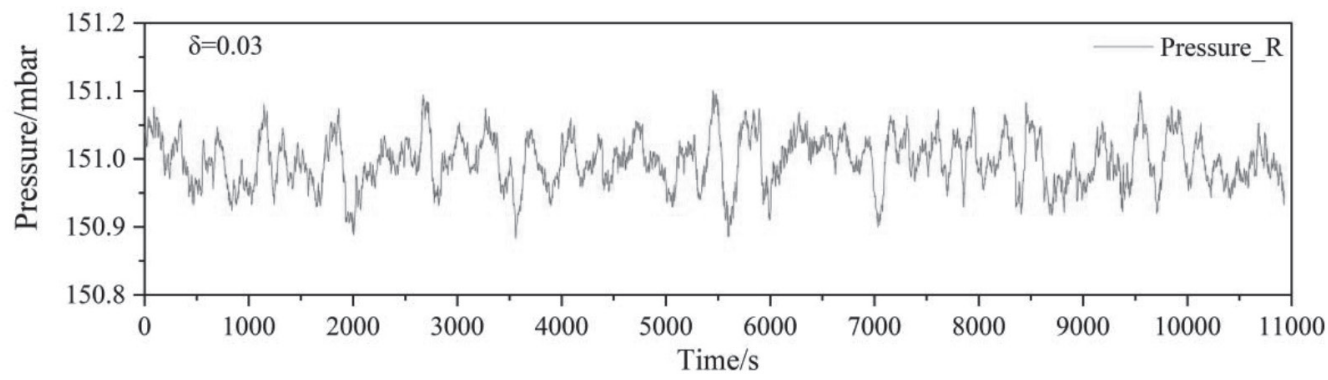

(b) Cavity pressure

Fig. 8. Waveform of cavity temperature and pressure continuous measurement for 3 hours.

the accurate control of temperature and pressure ensures the consistency of isotope measurement.

\section{Isotopic Detection Results}

To test the stability of the isotope measurement system with temperature and pressure control, the standard concentration of $5000 \mathrm{ppm} \mathrm{CH}_{4}$ is filled into cavity and the isotope abundance $\delta^{13} \mathrm{CH}_{4}$ is detected for 3 hours continuously. As can be seen from the original data in Fig. 9a), the $\delta^{13} \mathrm{C}$ value does not show a monotonous increase or decrease trend in a large range. The Allan variance analysis of $\delta^{13} \mathrm{C}$ isotope abundance obtained from the measurement results is carried out, and is shown in Fig. 9b). The measurement accuracy can be improved from $1.96 \%$ to $0.52 \%$ by 256 times average. Moreover, the latter half of Allan variance curve is still stable, and there is no upward trend, indicating that the overall stability of the system is good. This also fully proves the stability of the temperature and pressure control system for isotope measurement.

\section{Results and Discussion}

In order to satisfy the consistency of isotope measurement and solve the stability of optical

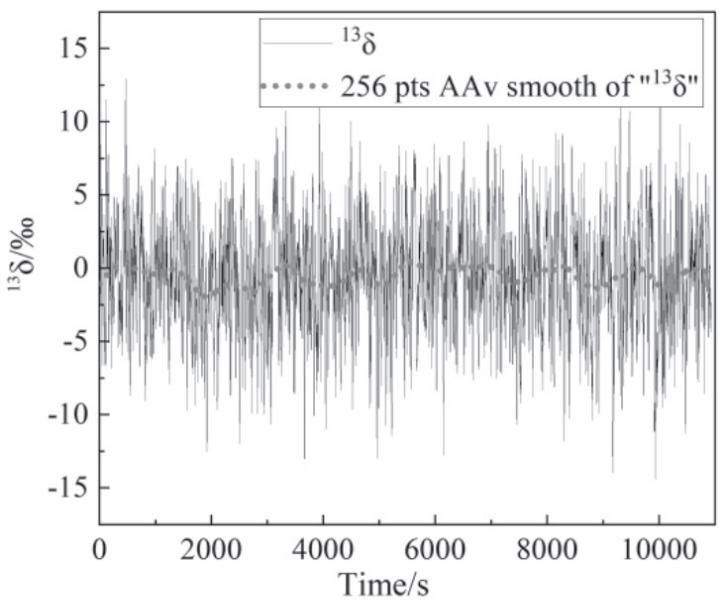

(a)Raw data and 256 pts AAv smooth of ${ }^{13} \delta^{\prime \prime}$

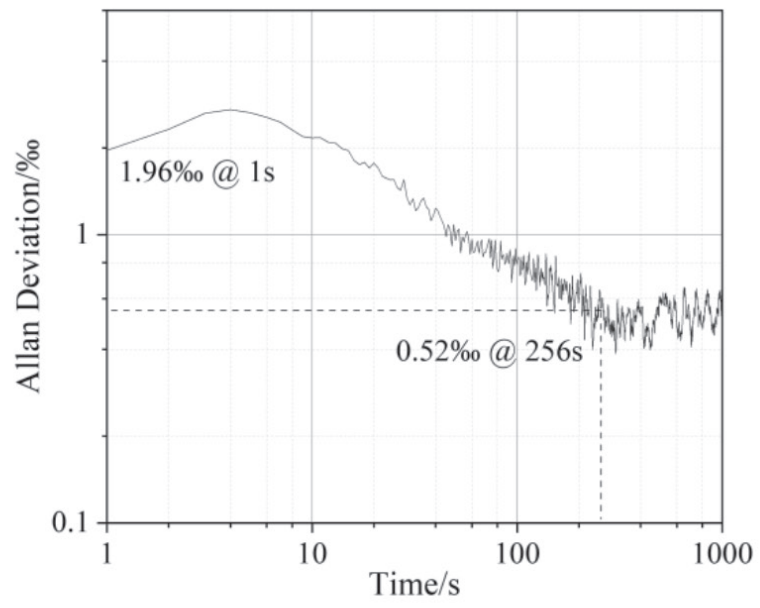

(b) 1000 s Allan variance

Fig. 9. Isotope measurements and stability analysis. 
mechanical structure, a set of cavity temperature and pressure control system is designed by selecting the appropriate control chip and PID control algorithm. The experimental results show that the system has the optimal temperature measurement accuracy of $35 \pm 0.005^{\circ} \mathrm{C}$ and standard deviation of less than $0.006^{\circ} \mathrm{C}$, the pressure stability of $150 \pm 0.1 \mathrm{mbar}$ and standard deviation of less than 0.03. Meanwhile, in order to verify the applicability, the isotopes of ${ }^{13} \mathrm{CH}_{4}$ standard gas with a concentration of $5000 \mathrm{ppm}$ are measured at room temperature of $26^{\circ} \mathrm{C}$ based on the TDLAS method. The isotopic measurement accuracy could reach $0.52 \%$ under the average condition of 256 times. Therefore, the above results further demonstrate the necessity of high precision temperature and pressure control for the isotopic measurement system.

\section{Acknowledgments}

This work is supported by National Natural Science Foundation of China (Nos. 11874364, 41877311, 42005107, 41773100), External Cooperation Program of Chinese Academy of Sciences (No. GJHZ1726), Key Research and development project of Anhui Province (Nos. 201904c03020005, 1804a09020097), Major scientific and technological projects in Anhui Province (No. 18030901054), Major projects of natural science research in Universities of Anhui Province (No. KJ2017ZD56), Support program for outstanding young talents in Colleges and universities of Anhui Province (Nos. gxyqZD2018072, gxyq2020061), Foundation of President of Hefei Institutes of Physical Sciences, Chinese Academy of Sciences (No. YZJJ2020N8).

\section{Conflict of Interest}

Ther authors declare no conflict of interest.

\section{Refernces}

1. JACOTOT A., MARCHAND C., ALLENBACH M. Biofilm and temperature controls on greenhouse gas $\left(\mathrm{CO}_{2}\right.$ and $\mathrm{CH}_{4}$ ) emissions from a Rhizophora mangrove soil (New Caledonia). Science of the Total Environment, $\mathbf{6 5 0}$ (1), 1019, 2019.

2. NICKLESS A., SCHOLES R.J., VERMEULEN A., BECK J., LOPEZ-BALLESTEROS A., ARDO J., KARSTENS W., RIGBY M., KASURINEN V., PANTAZATOU K., JORCH V., KUTSCH W. Greenhouse gas observation network design for Africa. Tellus, Series B: Chemical and Physical Meteorology, 72 (1), 1, 2020.

3. GAO F., WU T.W., ZHANG J., HU A.X., MEEHL G.A. Shortened duration of global warming slowdowns with elevated greenhouse gas emissions. Journal of Meteorological Research, 35 (2), 225, 2021.

4. OLLIVIER Q.R., MAHER D.T., PITFIELD C., MACREADIE P.I. Winter emissions of $\mathrm{CO}_{2}, \mathrm{CH}_{4}$, and
$\mathrm{N}_{2} \mathrm{O}$ from temperate agricultural dams: fluxes, sources, and processes. Ecosphere, 10 (11), 2019.

5. SANDS P. The United Nations Framework Convention on Climate Change. Review of European Community \& International Environmental Law, 1 (3), 270, 1992.

6. SETO K.C., DHAKAL S., BIGIO A., BLANCO H., RAMASWAMI A. Human Settlements, Infrastructure, and Spatial Planning. Intergovermental Panel on Climate Change, Cambridge University Press, 923, 2015.

7. SAUNOIS M., STAVERT A.R., POULTER B., BOUSQUET P., CANADELL J.G., JACKSON R.B., RAYMOND P.A., DLUGOKENCKY E.J., HOUWELING S., PATRA P.K. The global methane budget 2000-2017. Earth System Science Data, 12 (3), 1561, 2020.

8. DAHL-JENSEN D., ALBERT M.R., ALDAHAN A., AZUMA N., BALSLEV- CLAUSEN D., BAUMGARTNER M., BERGGREN A.M., BIGLER M., BINDER T., BLUNIER T. Eemian interglacial reconstructed from a Greenland folded ice core. Nature, 493 (7433), 489, 2013.

9. SARKODIE S.A., STREZOV V. Effect of foreign direct investments, economic development and energy consumption on greenhouse gas emissions in developing countries. Science of the Total Environment, 646, 862, 2019.

10. SARKODIE S.A., STREZOV V. Empirical study of the Environmental Kuznets curve and Environmental Sustainability curve hypothesis for Australia, China, Ghana and USA. Journal of Cleaner Production, 201, 98, 2018.

11. KANDEL T.P., LAERKE P.E., HOFFMANN C.C., ELSGAARD L. Complete annual $\mathrm{CO}_{2}, \mathrm{CH}_{4}$, and $\mathrm{N}_{2} \mathrm{O}$ balance of a temperate riparian wetland 12 years after rewetting. Ecological Engineering, 127, 527, 2019.

12. MORIN T.H., BOHRER G., NAOR-AZRIELI L., MESI S., KENNY W.T., MITSCH W. J., SCHAFER K.V.R. The seasonal and diurnal dynamics of methane flux at a created urban wetland. Ecological Engineering, 72, 74, 2014.

13. CAMBALIZA M.O.L., SHEPSON P.B., CAULTON D.R., STIRM B., SAMAROV D., GURNEY K.R., TURNBULL J., DAVIS K.J., POSSOLO A., KARION A. Assessment of uncertainties of an aircraft-based mass balance approach for quantifying urban greenhouse gas emissions. Atmospheric Chemistry and Physics, 14 (17), 9029, 2014.

14. PETERSON B.J., FRY B. Stable isotopes in ecosystem studies. Annual review of ecology and systematics. 18, 293, 1987.

15. MARX A., DUSEK J., JANKOVEC J., SANDA M., VOGEL T., VAN GELDERN R., HARTMANN J., BARTH J.A.C. A review of $\mathrm{CO}_{2}$ and associated carbon dynamics in headwater streams: A global perspective. Reviews of Geophysics, 55 (2), 560, 2017.

16. BIZIC M., KLINTZSCH T., IONESCU D., HINDIYEH M.Y., GUNTHEL M., MURO-PASTOR A.M., ECKERT W., URICH T., KEPPLER F., GROSSART H.P. Aquatic and terrestrial cyanobacteria produce methane. Science Advances, 6 (3), 2020.

17. ZENG J., HAN G.L., WU Q.X., TANG, Y. Effects of agricultural alkaline substances on reducing the rainwater acidification: Insight from chemical compositions and calcium isotopes in a karst forests area. Agriculture, Ecosystems and Environment, 290, 2020.

18. WILDE A.S., HANSEN A.M.S., FROMBERG A., FRANDSEN H.L, SMEDSGAARD J. Determination of $\delta^{13} \mathrm{C}$ of vanillin in complex food matrices by HS-SPME- 
GC-C-IRMS. Flavour and Fragrance Journal, 35 (4), 387, 2020.

19. A.D.SALEH M., SANTOS L.S, BERTO D.A., AMORIM A.B., TSE M., COSTA V.E. IRMS as a tool to obtain the carbon turnover $\left(\delta^{13} \mathrm{C}\right)$ in organs of weaned piglets fed glutamic acid and nucleotides. Journal of Animal Physiology and Animal Nutrition, 103 (3), 906, 2019.

20. MCINTYRE C.P., WACKER L., HAGHIPOUR N., BLATTMANN T.M., FAHRNI S., USMAN M., SYNAL H.A. Online ${ }^{13} \mathrm{C}$ and ${ }^{14} \mathrm{C}$ Gas Measurements by EA-IRMSAMS at ETH ZURICH. Radiocarbon, 59 (3), 893, 2017.

21. XIA H., DONG F.Z., HAN L., WU B., SUN P.S., ZHANG Z.R., CUI X.J. The Study of Atmospheric Carbon Isotope with Laser Absorption Spectroscopy at the Mid-Infrared Wavelength. Spectroscopy and Spectral Analysis, 37 (11), 3365, 2017 [In Chinese].

22. ZHANG Z.R., PANG T., SUN P.S., XIA H., LI Z., YU R.Q., SHU C.M. Measurement of carbon isotope of methane and analysis of its genesis yype using laser absorption spectroscopy. Chinese Journal of Lasers, 46 (12), 265, 2019 [In Chinese].

23. XIA H., DONG F.Z., WU B., ZHANG Z.R., PANG T., SUN P.S., WANG Y. Sensitive absorption measurements of hydrogen sulfide at 1.578. Chinese Physics B, 24 (3), 184, 2015 [In Chinese].

24. ZHANG Z.R., SUN P.S., XIA H., PANG T., WU B., CUI X.J., DONG F.Z. Modulation parameters influence and optimal selection of tunable diode laser absorption spectroscopy. Acta Photonica Sinica, 44 (1), 41, 2015 [In Chinese].

25. QI R.B., HE S.K., LI X.T., WANG X.Z. Simulation of TDLAS direct absorption based on HITRAN database. Spectroscopy and Spectral Analysis, 35 (1), 172, 2015 [In Chinese].

26. CHEN Z., TAO S.H., DU X.J., HOU X.J. Accurate calculation of spectral line profiles by considering influence of varying pressure and temperature in a gas. Spectroscopy and Spectral Analysis, 33 (2), 312, 2013 [In Chinese].

27. COOPER D.E., WARREN R.E. Frequency modulation spectroscopy with lead-salt diode lasers: a comparison of single-tone and two-tone techniques. Applied Optics, 26 (17), 3726, 1987.

28. GORDON I.E., ROTHMAN L.S., HILL C., KOCHANOV R.V., TAN Y., BERNATH P.F., BIRK M., BOUDON V., CAMPARGUE A., CHANCE K.V. The HITRAN2016 molecular spectroscopic database. Journal of Quantitative Spectroscopy and Radiative Transfer, 203, 3, 2017.

29. LYU Y., SIDDIQUE A.R.M., MAJID S.H., BIGLARBEGIAN M., GADSDEN S.A., MAHMUD S. Electric vehicle battery thermal management system with thermoelectric cooling. Energy Reports, 5, 822, 2019. 